\title{
APPLICATIONS OF CALLIGRAPHY FOR THE CREATION OF ARTWORKS OF AN INTERDISCIPLINARY NATURE
}

\author{
Svetoslav Kosev, Simeon Zhelev \\ "St. Cyril and St. Methodius" University of Veliko Tarnovo, Bulgaria \\ kosevsa@gmail.com
}

\begin{abstract}
European Calligraphy has a millennial history that has been marked by various stages and vicissitudes that influence modern aesthetic tendencies in calligraphy and typography. In the forthcoming conference will be presented some interesting examples of fundamental calligraphy scripts and their interpretations, as well as the preparation and realization of illustrations in graphic prints (lithography). The final result are artistic books inspired by Dante Alighieri's Divine Comedy poem, and in particular the Hell part, as well as Gustav Dore's graphics. The books are enriched with specially made cases, that further fortify the creative pursuits of the authors and to arouse interest in the viewer. The interdisciplinary approach and complex tasks, including 3D graphics and virtual reality, present a new read on book, illustration and calligraphy.
\end{abstract}

Keywords: Calligraphy; Interdisciplinary; Virtual Reality; 3D Graphics; Artistic Book; Lithography

\section{ПРИАОЖЕНИЯ НА КААИГРАФИЯТА ПРИ СЪЗААВАНЕ НА ПРОИЗВЕАЕНИЯ С ИНТЕРАИСЦИПАИНАРЕН ХАРАКТЕР}

\author{
Светослав Косев, Симеон Желев \\ Великотърновски университет "Св. св. Кирил и Методий", България
}

\begin{abstract}
Резюме: Европейската калиграсрия има хилялолетна история, която е белязана от размични етапи и превратности. Те оказват влияние на съвременните естетически тенденции в графричния Аизайн, типографията и изкуството $А$ пишем красиво. На прелстоящата конференция се представят няколко примера за основни калиграфрски шрифртове и техните интерпретации, както и полготовката и реализацията на илюстарции в графичен отпечатък (Аитографрия). Крайният резултат са артистични Книги, вАъХновени От поемата "Божествена комедия" на Аанте Алигиери и по-конкретно частта "АА", и приАружаващите графики на Густав Аоре. Артистичните книги са полпАьтени в специално съзАадени кутии, които АопьАнително обогатяват творческите тьрсения, преАизвиквайки интерес у зрителя. ИнтерАициплинарния поАхоА и поставените комп^ексни залачи, които вкАючват триизмерна графрика, виртуа^на реалност, ^итографрия, книжен Аизайн и т.н., представят нов прочит върху книгата, илюстрацията и калиграфията.
\end{abstract}


КАючови Ауми: калиграфрия, интерлисциплинарен, виртуанна реалност, триизмерна графика, артистична книга, ^итография

Хи^ядолетната еволюция на европейската Калиграфрия е белязана от различните културни епохи и исторически превратности. Те оказват влияние на съвременните естетически тенденции в графоичния Аизайн, типографрията и изкуството да пишем красиво. През вековете възникват множество калиграфрски шрифртове, които в послеАствие влияят на създаването на типографоските шрифртове (Yonchev, 1971), (Gogov, 2018), (Meulman, Eeuwens, 2013), (Hundertmark, Hartl, 2017), (Harris, 1995). Основните и най-влиятелните калиграфрски образци в европейската тралиция на красивото писане са: капиталис монументалис, който преди да бъле "изрязян" в камька е изписван с четка, капиталис квалрата, унциал, каролингски минускул, текстура квалрата, ротунда, фррактур, швабахер, хуманистичен минускул, канчелареска или т. нар. италик, копьрплейт или т. нар. англе. В българската тралиция в изписването на кирилицата имаме три силно характерни шрифта: устав, полу-устав и везани букви (вяз).

В художествения проект, в който взех активно участие: "Превьп^ьщенията на книгата", използвам някои от изброените по-горе калиграфоски шрифтове. Всеки еАин от тях има свое звучене, пропорция и характерни елементи. Използваните шрифртове разбира са с леки изменения и интерпретации, за $\Delta$ а могат напь^но $\Delta$ а се потопят в тематиката и сюжета.

Илеята за този проект Аойле от Аоц. Косев, като аз бях поканен в малко по-късен етап. В началото целта бе $\Delta а$ се направят серия графиики по митературни произведения. В процеса на фокусиране и изчистване на илеята доц. Косев се спря върху вАьхновяващата книга "Божествена комедия" на Аанте Алигиери и по-конкретно частта "АА". Зал този проект стои и друга илея, $\Delta$ а се реализира художествено произведение чрез редица техники и методи, които се различават съществено, като се цели да се стимулира експериментирането, освобожАаване от невидимите граници в художествените среАи, както и $\Delta \mathrm{a}$ се разширят способите за създаване на произведения в изобразителното изкуство. Тази интерАисциплинарност в конкретния 
случай включи в себе си тримерна графрика, 3D скулптиране, софртуер за двуизмерна графрика, калиграфията и т.н. Крайните хуложествени продукти от проекта „Превьпльщенията на книгата" бяха представени пол фрормата на ръчно изписани калиграфрски налписи, Аитографрски отпечатьци, рьчно съзАадени книги и кутии към тях, както и виртуална реалност.

В неорормален разговор с Петър Аазаров (виден художник в областта на графичнните изкуства и изкуството на книгата), Аоц. Косев реши $\Delta а$ обогати своята концепция С АопьАнитеАни артистични книги

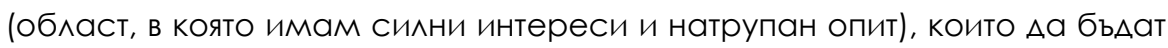
съзАалени от някои от литографските отпечатъци. Освен калиграфрските текстове, аз се заех и с ръчната изработка на книгите-обекти или т.нар. още артистични книги. За всяко еАно произведение, което съзАале Аоц. Косев, се подготви по еАна бройка артистична книга (уникат). Процесите и интерАисциплинарните подходи, през който се премина, неимоверно обогатиха крайните художествени произведения (^итографрските отпечатъци и артистичните книги). Чрез комбинирането на различни техники и метоли, както и проведените експерименти, заедно с Аоц. Косев съзАалохме проект, който наАхвърля границите на всеки еАин метол и техника взет по отАелно. Книгата, илюстрацията, съпьтстващата калиграфрия, вече могат да бъдат приети по-нов и различен начин.

В проекта "Превьпльщенията на книгата" използвам найразлични изразни средства. За всяка еАна артистична книга и калиграфоки наАпис изпо^звам сравнитеАно схоАна послеАоватеАност на работа, въпреки това експериментите не са малко и често се случва

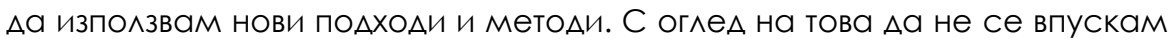
в Аопьлнителни размишления, ще се фокусирам нал еАно произведение и етапите на работа, характерни за него.

Всяко еАНо От СъзАалените произвеАения, коИто са част от художествения проект „Превъпльщенията на книгата" започва с $о$ ". Косев. По свое усмотрение и творчески тьрсения той решава и избира коя песен (част) от "АА" на Аанте А^игиери да изпо^зва за вАьхновение, за $\Delta а$ съз $а$ ае своето произведение. В малко по-късен етап, когато има вече ясно определена композиция, аз се намесвам, като създавам 
калиграфоски налписи, които са част от текста на конкретната песен. Калиграфията и нейното композиране се решава така, че $\Delta а$ се полчертаят фрормите и водещите линии. Понякога калиграфрския налпис е сьставен от цяла строфра, а понякога от отАелни стихове. Но това решение зависи от предварително залалената композиция и илеята текста $\Delta а$ бъле съобразен със създаленото изображение. Така текстьт става подвластен на илюстрацията, обратното на това, което е прието в литературата - илюстрацията е полвластна на текста. Тази обьрната концепция загатва демоничното звучене, което е в синхрон с тематиката и цялото произведение на Аанте.

Всеки еАин калиграфрски шрифт, който съм използвал се премисля и скицира внимателно преАи Аа бьле приложен кьм художествената интерпретация на Аоц. Косев (фоиг. 1). Значителна част от калиграфриите са готически и носят по-агресивно звучене. Причината за това е, че много от илюстрациите са свързани с Аемони и тъмни същества описани в "АА", които, Аогично, носят негативно звучене или са агресивно настроени. Аруга причина е, че много от религиозните текстове също са изписани с готически шрифртове, което съзАава впечатлението за художествена творба базирана на религиозни текстове.

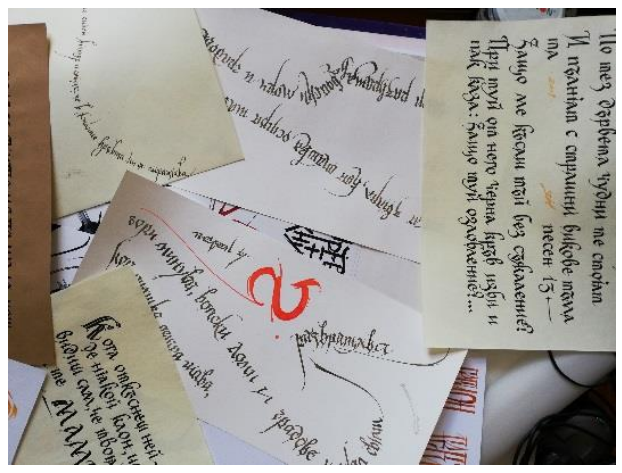

фиг. 1 ПоАготвителни скици.

В произведението „Аанте Алигиери-Божествена комедия-песен 13" (фииг. 2) включих няколко калиграфрски текста, които са взети, както името говори, от песен (част) тринайсета на "АА" от „Божествена комедия" на Аанте Амигиери. 


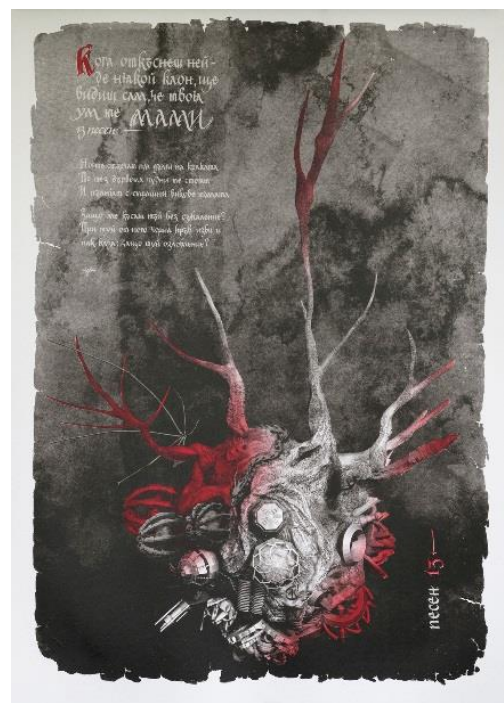

\section{фиг. 2 „Аанте Алигиери-Божествена КомеАия. Песен 13“}

Използвани са Аве строфри и Ава стиха с текст, които най-Аобре описват и комуникират със съзАаленото изображение. Тази аморорна структура съчетана с редица механични и органични части много Аобре описва текста:

„нокте стьрчат им Аьлги на краката,

по тез Аьрвета чудни те стоят

и пь^нят с страшни викове тьмата."

"Защо ме кьсаш тьй без сьжаление?"

При туй от него черна крьв изби

и пак каза: „Защо туй озлобление?"

Особено пьрвата строфра, много ясно и категорично може $\Delta а$ повлияе на зрителя в своята представа, а втората стросра $А$ въздейства върху емоционалното му състояние. Пьрвата строфра ми преАостави контекста, в който Аа мисля за вида калиграфрски шрифт. ИАеята за к^они, Аьрвета и Аьлги нокти на краката, остана в съзнанието ми. Начупеността и разк^оняването бяха водещи при изписването (фриг. 3). 


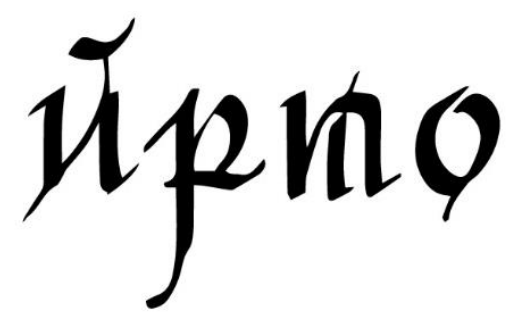

фиг. 3 Калиграфски букви "й", "р", "т", "о", част от

новосъзАаАения калиграфски шрифт.

Като волещи калиграфрски шрифртове използвах елементи от Ранно готическия шрифрт, който има межАинна роля и се явява като прехоА от античност кьм готика (от Унциал кьм Текстура квалрата) и елементи от реАОвните букви от калиграфрския шрифт Фрактур (фии. 4) със заострените си и агресивни завьршвания. В случая реших Аа не използвам силното начупване от Фрактур, за да не стане прекалено тежък.

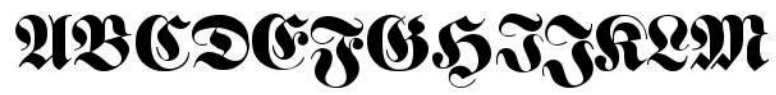

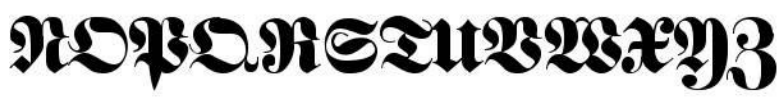 abciejghijlilm mopqratuwwayd $0123456889 ! ? \#$ фиг. 4 фрактур}

На места използвам все още присьстващата мекота от Ранно готическия шрифт (фриг. 5), което препраща към аморорността на главното изображение.

А агресията и заострянето от Фрактур, напомнят на к^оните и Аьлгите нокти на краката. Разбира се трябва да спомена пропорциите на калиграфския текст. Те са съобразени отново с готическите шрифртове. Ръчно изписаните букви са с кондензирани пропорции и сравнително кьси асцендьри и лесцендьри, за сметка на това 
межАуредовото пространство е увеличено, за да не създават твърАе тежки петна в картинното пространство, както и $а$ не привличат твьрАе много внимание от акцента - аморорната сорера.

\section{abedefoghyklmno pqusetuvwxyz}

фиг. 5 Ранно готически шрифт

На фриг. 3 и фриг. 6 се може да наблюдаваме мекотата от ранно готическия шрифот и всички излизания от буквите, който Аават усещането за разклонение. За Аа прилобият буквите още повече характер, използвах и триъгьлно "а" (вАъхновено от шрифрта Унциал), от което изведох и буквите „м“, „^" и „я" (ффиг. 6). В Конкретния случай в шрифта Унциал не присъстват кирилските знаци. Затова използвах Аруг тип изписване на буквата, с малко по-старовремски прицип, в който буквата е съставена от Аруги Аве букви (Аигатура): „и“ и „а“ (фриг. 6).

\section{AגMOiג}

фиг. 6 Част от буквите, вАъХновени от шрифта Унциал.

СлеА като уточних И извеАох всички нужни ми букви за калиграфокия шрифт към произведението "Аанте АлигиериБожествена Комедия. Песен 13", пристьпих към неговото реализиране. Всичко премина по традиционния начин за калиграфрията. Плоско скосено метално перо, перодръжка, туш и специална хартия, която нито $А$ п попива твърле много, нито да зальржа туш. Композирането на текста се реши също в традиционен стил с текстово каре полравнено от^яво. За разлика от Аруги текстове (в следващите художествени произведения от проекта „Превьпльщенията на книгата"), някои от които бяха композирани по криви минии (фриг. 7). 


\section{СВЕТОСААВ КОСЕВ, СИМЕОН ЖЕАЕВ}

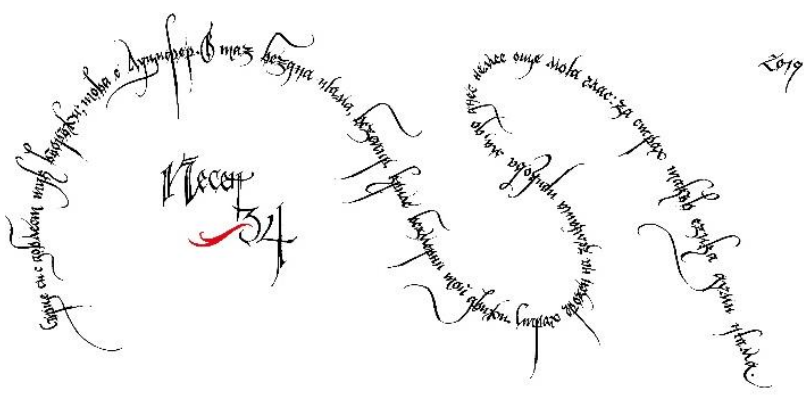

фиг. 7 Калиграфскии текст по крива.

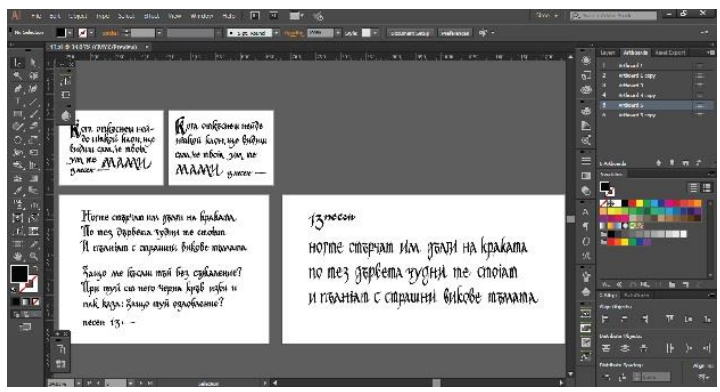

фиг. 8 Финален вариант в софтуер за векторна графика

Слел този тралиционен за калиграфрията процес на рьчно изписване, се пристьпи кьм неговото подготвяне за Аигитална обработка. Сега илва въпроса, ако елин калиграфрски шрифрт ще бъле Аигитализиран, какъв е смисьла той $а$ бъде правен по конвенционалния начин. Причината е, че въпреки всичко, перото, туша и хартията оставят следи, текстури, които съчетани с красивите букви съзаават богатство от форми, петна и минии. А това е и еАна от иАеите на Аоц. Косев: съчетание на Аигиталното с аналоговото. За Аигитализацията се премина през няколко етапа. Пьрвият е сканирането, чрез което не се губи детайл от качеството на изображението и се избягват перспективните изкривявания, които биха могли да се появят при заснемането с фотоапарат. Следващата стьпка премина през софртуери за векторна (фог. 8) и растерна обработка, които се ползват най-вече $\Delta а$ се полготви калиграфрския текст за финалното Аигитално произведение. Освен това се правят и ^еки 
поправки в разрялката, межАубуквеното пространство или конструкцията на някои букви (ако има такава нужАа).

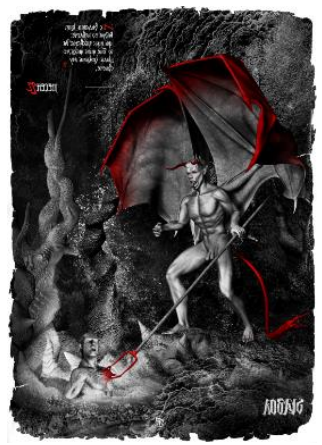

\section{фиг. 9 Огленален изглеА, полготовка за митографско отпечатване.}

При завършването на Аигиталното произведение с всички свои композиционни особености, фригури, минии, текстури, калиграфрски налписи и т.н. Аоц. Косев полготвя творбата за отпечатване в техниката митографрия. Тук няма $\Delta а$ се впускам в подробности, но накратко казано, изображението се обрьща оглеАално и се прави цветоотАелка (ако крайният митографрски отпечатък ще е с повече от еАин цвят). Всичко това е породено от специфииката на техниката ^итографрия. При която, за $а$ п постигнем нужния резултат, трябва $А$ о обрнем оглелално изображението (фриг. 9). СлеА отпечатването от митографрския камък (в конкретния случай алуминиева плака) изображението отново се обръща огледално, т.е. то става с оригиналния си вил, преАвилен, в началото. В Аопьлнение на това, ако искаме да имаме повече от еАин цвят, се правят АопьлнитеАно камьни (или алуминиеви плаки), които Аа са сьставени само от елементи на изображението с нужния цвят, като се отпечатват върху вече направения отпечатък.

Самият процес на отпечатване също има Аопьлнителни специфики, но те не са в моята специализация. Урмдрукерьт Румен Райков също се включи в проекта ръковолен от Аоц. Косев. Райков спомогна със своите знания в областта на литографията, като отпечата по профресионален начин митографрските отпечатьци (фриг. 10). финалните митографрии бяха в ограничен тираж, като за всяка елна 
творба отАелихме с Аоц. Косев по еАно копие за съзАаването на книгите и приАружаващите ги кутии.

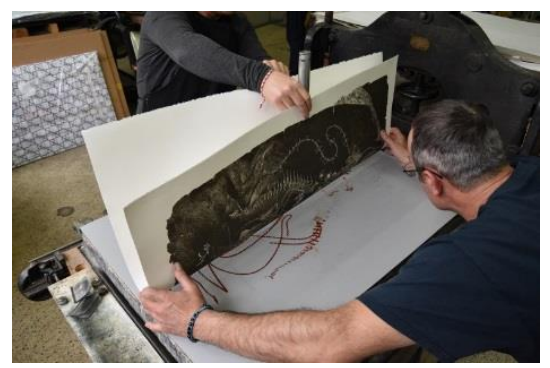

фиг. 10 Румен Райков и процесът на литографско отпечатване.

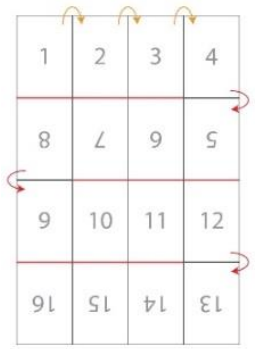

фиг. 11 Схема за изрязване и сгъване за създаване на ко́ла.

Всяка еАна ко́ла от КнижНОто тялО е СъзАаАена На СХОАНа основа, но в последствие с придружаващи експерименти, които са уникални за всяка книга и кутия. Схемата за съзАаване на всяка еАна кó^a е слеАната - литографрският отпечатьк се разАеля на четири равни реда и колони, образувайки 16 страници (всяка еАна книга е съставено от 16 страници). По тази схема се подрязва листа по определен начин (червените контури, които редуват посоките си), като в последствие елементите се сгъват сьчетавайки се в една ко́ла (фриг. 11).

Интересен момент в този тип изрязване и сгъване е, че се съзАава на случаен принцип композиция и послеАОвателност в странирането на книгата. Някои страници стават огледални на Аруги, което води Ао най-разнообразни резултати. Също така странирането „изрязва" цялото изображението и съзАава разказ в полу-абстрактни по- 
малки изображения, което Аава предпоставки за Аопьлнителни смислови значения (тук се разчита предимно на въображението на зрителите). За да стане все пак цялостна книга, се Аобавят корици, които $\Delta а$ бьлат в тон с художественото произведение. В конкретния случай, който е свързан с песен 13 от "АА" на Аанте А^игиери, се постарах корицата $а$ а бъле в тон с цветовата гама на Аитографрския отпечатьк. Черният цвят е преоблалаващ, а червеният се използва за акцент. Аобавих черни текстури, като използвах и техника на колажиране, за да придам Аопьлнителен обем на книгата. Към корицата на книгата са Аобавени различни по виА И цвят хартия, боялисан с черен спрей Аьрвен фрурнир и кора от Аърво. Аьрвото, разбира се, е препратка към текста и основния обект (амороната планета фриг.2) на литографрския отпечатьк. Кутията към книгата се разви по схолен начин, като целта ми бе $а$ а наподобя максимално аморонната планета. Колажът е волещата техника използвана при създаването на кутията. Метал, Аърво, стък^о, пясък, въ^на и Ар. са комбинирани по такъв начин, че $А$ С симулират и Аопьлнително $А$ а представят в пространствен обект сцената от песен 13. Позволих си също така $\Delta а$ използвам и калиграфия по корицата на книгата и кутията. При корицата заложих скрит текст, който $А$ накара зрителя $\Delta а$ се потопи в имагинерния свят, представен от Аоц. Косев. А при кутията

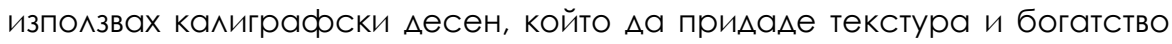
във формите. Крайният резултат на произведението "Аанте АлигиериБожествена Комедия. Песен 13" са митографрски отпечатък в ограничен тираж, книга и придружаваща кутия към нея (фриг. 12).

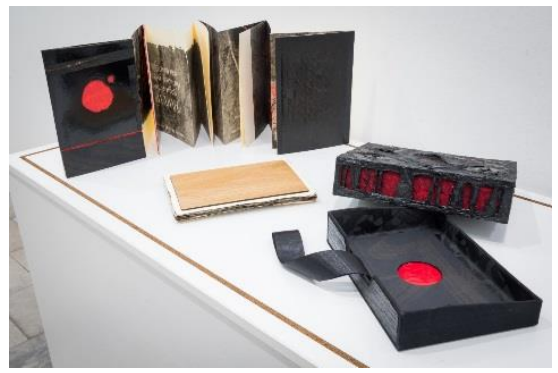

фиг. 12. Книга и приАружаващата я кутия. 


\section{ЗАКАЮЧЕНИЕ}

ИнтерАисциплинарността на проекта "Превьп^ьщенията на книгата" е нужна поради комплексността на поставения проблем от Аоц. Косев. На прьв поглеА калиграфията не е нужна, но при решението от създаване на книжен носител и неговото издигане на Аруго ниво, калиграфрията става Аопьлнителен проводник на илеи. Нейната реализация открива нови хоризонти и Аава Аопьлнителни хуложествени, естетически и философоски пластове, от които зрителя може $\Delta а$ черпи инорормация и илеи. Приложението на калиграфрията може $\Delta а$ бъле използвано, както в тралиционни фрорми на изкуството, така и в най-различни технологични и съвременни проекти свьрзани с визуалните изкуства. Тя е еАин Аопьлнителен инструмент в арсенала на еАин художник. Без нея може, но с нея светьт оживява и става по-красив.

\section{МИTEPATYPA / REFERENCES}

Gogov, Kiril (2018). ABV Grafichen Dizajn, Kniga Vtora (in Bulgarian), Publisher: NHA, Sofia, Bulgaria, book 2, ISBN 978-954-2988-45-8 // [Гогов Кирил "АБВ Графричен Аизайн" Книга втора [Книга]. - Софрия : HXA, 2018. - Том II. - ISBN 978-954-298845-8].

Harris, David (1995). The Art of Calligraphy: A Practical Guide to the Skills and Techniques. - London : DK ADULT, 1995. - ISBN-10: 1564588491.

Hundertmark, Christian; Hartl, Patrick (2017). The Art of Writing Your Name: Contemporary Urban Calligraphy and Beyond, Publisher: Publikat Verlags- und Handels GmbH \& Company KG, 2017, p. 288, ISBN: 978-3-939566-50-2 // [Hundertmark Patrick Hartl \& Christian The Art of Writing Your Name: Contemporary Urban Calligraphy and Beyond [Книга]. - Germany : Publikat, 2017. - ISBN: 978-3-939566-50-2].

Meulman, Niels Shoe; Eeuwens, Adam (2013). Calligraffiti: The Graphic Art of Niels Shoe Meulman, Publisher: From Here to Fame Pub., 2010, ISBN 978-3-937946-21-4 // [Meulman Niels "Shoe" Calligraffiti [Книга]. - Berlin : From here to fame publishing, 2013. - ISBN 978-3-937946-21-4].

Yonchev, Vasil (1971). Shriftat prez vekovete (in Bulgarian), Publisher: Balgarski hudozhnik, Sofia, Bulgaria, 1971 // [Йончев Васи^ Шрифртьт през вековете [Книга]. - Софрия : Български художник, 1971]. 


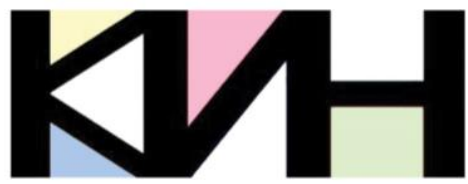

КУАТУРНО-ИСТОРИЧЕСКО НАСАЕАСТВО:

ОПАЗВАНЕ, ПРЕАСТАВЯНЕ, АИГИТААИЗАЦИЯ

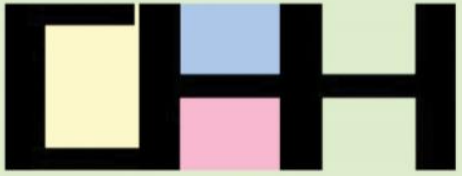

CULTURAL AND HISTORICAL HERITAGE: PRESERVATION, PRESENTATION, DIGITIZATION
Материалите в сборника са обект на авторско право. Разрешава се безвъзмезАното ползване на техни електронни/ хартиени копия само за лична употреба или обучение, при пь^но цитиране на текущата страница и слеА писмена декларация от цитиращия за мипса на търговски намерения.

(с) Авторски колектив, 2020

Техническо реАактори: Калина Сотирова-Вълкова Николай Ноев Паска^ Пиперков

\section{Editors}

Petko St. Petkov

Galina Bogdanova

This work is subject to copyright. Open and free of charge use of digital/hard copies of publications is granted only for personal or educational use, with full citation of the current page, and after written declaration of the quoting side for notcommercial Intention.

(C) Authors` Group, 2020

Technical editors:

Kalina Sotirova-Valkova

Nikolay Noev

Paskal Piperkov

НАЦИА регистрационен № 1209

Научна пореАица: том 6, брой 2 (9)/2020

Science series: vol. 6 , issue $2(9) / 2020$

NCID Registry No. 1209

www.math.bas.bg/vt/kin

ISSN: 2367-8038 